\title{
4
}

\section{Sobre la concepción de lo religioso en Wittgenstein: un socioanálisis}

\author{
On Wittgenstein's conception of the religious: a \\ socio-analysis
}

\author{
FERNANDO ROCHER QUINTAIROS \\ Universitat de València \\ nandorocher@gmail.com \\ ORCID ID: https: / / orcid.org/0000-0003-0290-2246
}

\section{Resumen}

Con motivo del centenario de la publicación del Tractatus Logico-philosophicus, esta ocasión pone de nuevo en relevancia a una de las grandes figuras de la filosofía del siglo XX, Ludwig Wittgenstein. Este autor, de manera directa o indirecta, ha realizado aportaciones no solo a la filosofía, sino a gran variedad de ramas de pensamiento, entre ellas a las ciencias sociales. No obstante, y paradójicamente, las ciencias sociales en general, y la sociología en especial, no han prestado mucha atención a Wittgenstein más allá de algunos aspectos epistemológicos y metodológicos de su filosofía. Es por ello que consideramos que un estudio específicamente sociológico sobre la figura personal de Wittgenstein, enlazado con su concepción filosófica y en concreto sobre el fenómeno religioso, podría servir para aportar mayor claridad y comprensión conceptual a estos mismos planteamientos wittgensteinianos que las ciencias sociales han adoptado dentro de sus teorías e investigaciones.

Palabras clave: Wittgenstein, socioanálisis, religión, filosofía, Tractatus.

\section{Abstract}

To mark the centenary of the publication of the Tractatus Logico-philosophicus, this occasion once again highlights one of the great figures of 20th century philosophy, Ludwig Wittgenstein. This author, directly or indirectly, has made contributions not only to philosophy, but also to a wide variety of branches of thought, including the social sciences. Paradoxically, however, the social sciences in general, and sociology in particular, have not paid much attention to Wittgenstein beyond some epistemological and methodological aspects of his philosophy. This is why we believe that a specifically sociological study of Wittgenstein's personal figure, linked to his philosophical conception and religious phenomenon, could serve to bring greater clarity and conceptual understanding to these same Wittgensteinian approaches that the social sciences have adopted in their theories and research.

Key words: Wittgenstein, socioanalysis, religion, philosophy, Tractatus. 


\section{INTRODUCCIÓN}

Con motivo del centenario de la publicación del Tractatus Logico-philoaophicus, esta ocasión pone de nuevo en relevancia a una de las grandes figuras de la filosofía del siglo XX, Ludwig Wittgenstein [1889-1951]. Este autor, de manera directa o indirecta, ha realizado aportaciones no solo a la filosofía, sino a gran variedad de ramas de pensamiento, entre ellas a las ciencias sociales. No obstante, y paradójicamente, las ciencias sociales en general, y la sociología en especial, no han prestado mucha atención a Wittgenstein más allá de algunos aspectos epistemológicos y metodológicos de su filosofía. Es por ello que consideramos que un estudio específicamente sociológico sobre la figura personal de Wittgenstein, enlazado con su concepción filosófica, podría servir para aportar mayor claridad y comprensión conceptual a estos mismos planteamientos wittgensteinianos que las ciencias sociales han adoptado dentro de sus teorías e investigaciones.

Enmarcado en una investigación más amplia bajo la forma de un socioanálisis que toma como modelo el trabajo realizado por Bourdieu a propósito de Martin Heidegger y su ontología [Bourdieu, 1991], aunque a una escala mucho menor, este ensayo recoge una primer esbozo o aproximación sociológica a la figura de Wittgenstein a través de una categoría propiamente social como es la religión, ya que la religiosidad expresada por Wittgenstein en sus escritos parece presentar características diferenciales significativas que merecen esta atención desde una posición sociológica. Se busca por tanto establecer una relación de carácter teórico-conceptual, a la vez que provisional debido a su condición propedéutica de exploración y aproximación a la temática, entre la figura personal de Wittgenstein y sus planteamientos filosóficos a través de una caracterización sociológica de su religiosidad.

La cuestión de la elección de lo religioso como objeto de estudio se debe a dos razones de carácter metodológico específicas del propio objeto a tratar. Por una parte, [1] la religión como hecho social es un objeto propiamente sociológico; es por tanto una vía óptima para hacer aflorar los elementos sociológicos implícitos en concepción de la religión de Wittgenstein que, a nuestro parecer, está en estrecha relación con sus concepciones filosóficas, pudiendo derivar así una consideración de lo social en general. Por tanto, uno de los puntos a defender en este trabajo es que, en su concepción de la religión, Wittgenstein es coherente y consecuente tanto con su labor y producción filosófica como en su propia concepción de aquello que llama "forma de vida", en la que se comprende lo social. Por otra parte, [2] esta concepción de lo religioso en Wittgenstein es, incluso dentro de una rama de conocimiento tan diversa, plural y ecléctica como la filosofía, de una peculiaridad curiosa. Es especialmente remarcable lo propiamente único de la concepción de Wittgenstein ya no de la religión en general, sino la suya propia y personal, que en cierta manera se desmarca de la mayoría de concepciones tradicionales o habituales, incluso dentro de su propia consideración del fenómeno religioso. Consideramos que esta concepción peculiar puede suponer un efecto de contraste muy marcado que puede hacer aflorar con más claridad los elementos propiamente sociológicos frente a una exploración de su posición filosófica en general.

Es por estas razones que el presente ensayo toma como objeto la concepción de la religión de Wittgenstein y la problematiza en dos aspectos: [1] cuestiones generales respecto a su concepción de lo religioso y [2] la concepción de su propia religiosidad personal e individual. A partir de este 
objeto nos planteamos como objetivo, en primera instancia, una caracterización en cierta manera similar a un "tipo ideal" 1 de la religiosidad wittgensteiniana en los dos aspectos mencionados, y la cual, a nuestro parecer, va de la mano de su concepción filosófica. A continuación, y sobre lo elaborado en esta caracterización, intentamos derivar una relación de carácter conceptual entre [1] la condición personal del autor, [2] su religiosidad propia, [3] su consideración de lo religioso en general, [4] su posición filosófica y [5] su consideración frente a lo social y su articulación [grupos, comunidades, etc.].

Para este fin trabajamos sobre distintos materiales del propio Wittgenstein o en referencia a él, siendo estos [1] los Movimientos del pensar, Diarios 1930-1937/1936-1937, (2) Aforismos: Cultura y Valor, [3] el Tractatus Logico-Philosophicus, [4] las Investigaciones Filosóficas, y [5] diversos textos y fragmentos de distintos períodos de procedencia ${ }^{2}$. Queremos puntualizar que siendo este trabajo una primera aproximación conceptual, los textos y fragmentos se han seleccionado en consideración de su pertenencia y adecuación al objeto de estudio y la facilidad para la construcción del modelo teórico. En cuanto al aparataje conceptual sociológico utilizado para el análisis se extrae de la obra de diferentes autores, específicamente Weber, Durkheim, Veblen y Bourdieu.

En lo metodológico procedemos, en un primer momento, al análisis de los textos y materiales de Wittgenstein, de los cuales se extraen aquellos fragmentos, pasajes y elementos que puedan resultar útiles para la caracterización sociológica que se pretende elaborar. Este análisis se realiza ya a través de conceptos sociológicos, por tanto, consideramos importante hacer la advertencia preliminar de que lo que aquí se pretende es la transformación de una concepción filosófico-religiosa en una concepción sociológica, y por tanto expresada en otros términos, con otros sentidos y con diferentes intenciones. En este sentido nos adscribimos metodológicamente a las configuraciones por constelaciones propias de autores como Benjamin o Adorno: sólo tomamos en consideración aquellos aspectos que puedan resultar fecundos en la caracterización sociológica del objeto que, sin embargo, nunca pierde de vista su concepción filosófica original, ya que, a la vez, ésta misma es un elemento constitutivo del análisis y la constelación que se intenta elaborar, sobre todo en el momento sintético; simplemente, ya no es el elemento central del análisis como podría serlo en una concepción puramente filosófica. En otras palabras, si en esta transposición a conceptos sociológicos para el socioanálisis se traicionan el sentido de algunos de los elementos filosófico-religiosos originales, solo podemos aquí disculparnos por adelantado.

Todo lo expuesto en el párrafo anterior corresponde a un primer momento analítico en el cual se abstraen los elementos que conforman el "tipo ideal" de la religión para Wittgenstein. Ahora bien, el resultado de este análisis no es una forma unitaria acabada que comprendería la concepción de la religión de Wittgenstein como totalidad racional y comprensiva, sino que, como elementos abstraídos analíticamente, estos deben ser puestos en relación o, como diría Marx en 1857, las determinaciones abstractas conducen a la reproducción de lo concreto por el camino del

\footnotetext{
$1 \quad$ Se alude aquí de manera directa a un instrumento propiamente weberiano por su utilidad para describir el tipo de caracterización que se pretende, pero se usan las comillas debido a que la alusión no es en sentido enfático, sino intuitivo. Como se verá más adelante, aquí se le da un uso más próximo a lo que se podría llamar un objeto de conocimiento o esencia, una categoría de mediación, cuyo resultado es un modelo. Aun así, se mantiene en este punto la terminología weberiana debido a su conveniencia expositiva y a que, en cierta manera, mantenemos el carácter de "exageración de las características" implícita en un tipo ideal al pretender una trasposición de conceptos filosófico-religiosos a conceptos sociológicos.

$2 \quad$ Todas las citas corresponden a Wittgenstein y se ha optado por citar el texto publicado y la página.
} 
pensamiento [Marx, 2010] ${ }^{3}$. En otras palabras, una vez se ha procedido a la caracterización [trasposición] sociológica de los elementos filosófico-religiosos, estos deben ser relacionados teóricamente entre ellos para reconstruir la realidad de la que se han abstraído, expresando ahora esta realidad en clave social y, a la vez, reinsertando los elementos filosóficos y religiosos originales en un nivel de estudio propiamente social o, en otras palabras, convirtiendo estos elementos en manifestaciones existentes explícitamente en el nivel social. Este es el momento del socioanálisis propiamente dicho, en el que los distintos elementos abstraídos son atravesados por la mirada sociológica y se ponen en relación, ahora sí, como una "totalidad determinada". En otros términos, aquí los elementos filosófico-religiosos son arrancados de una dimensión abstracta y se insertan en un contexto social el cual atraviesa los distintos aspectos sociales implícitos en el ámbito filosófico-religioso y, en los términos de Foucault, los hace emerger, poniendo en relación simultánea cada uno de estos aspectos y a la vez enmarcándolos en este contexto.

Nos gustaría apuntar también, a modo de aclaración, que, aunque la investigación que ocupa este ensayo se presenta aquí en dos momentos, estos no están separados en sentido estricto; lo que prima realmente es el proceso de investigación y producción del conocimiento, el cual comprende ambos momentos como igualmente importantes, y no el mero resultado. El análisis ya supone en su mismo proceder la relación entre abstracciones que conforma el objeto de conocimiento o, en otras palabras, una categoría de mediación. Por su parte, el momento "sintético", poner las relaciones en sentido teórico, requiere de y actúa sobre los elementos abstraídos y su conformación como objeto de conocimiento para proceder a su reconstrucción teórica, el socioanálisis en sentido estricto, como conocimiento propiamente dicho de carácter reflexivo. En este sentido, el método aquí utilizado es también dialéctico.

El objetivo de este ensayo es que la "totalidad determinada" como desarrollo resultante sirva para poner en relación lo personal, lo religioso, lo filosófico y lo social, como dimensiones solapadas y recíprocas, en referencia a la figura de Wittgenstein, la cual junto a su concepción filosófica de la religión es siempre el objeto central.

\section{CARACTERIZACIÓN SOCIOLÓGICA DE LA CONCEPCIÓN DE LO RELIGIOSO EN GENERAL EN WITTGENSTEIN}

Debido a que la concepción de la religión de Wittgenstein, como ya se ha apuntado más arriba, se presenta con un carácter fragmentario y esparcida por diversos textos y manuscritos, no vamos a abordar aquí la tarea del análisis de un modo "sistemático", sino que, siguiendo el modelo de las constelaciones ya mentado, optamos por extraer fragmentos seleccionados los cuales consideramos pertinentes para la caracterización sociológica que pretendemos.

\footnotetext{
3 En este sentido, lo que aquí llamamos "tipo ideal” es más bien un recurso analítico para caracterizar el resultado del primer momento, y no un instrumento heurístico como lo sería en su acepción propiamente weberiana; aquí, como caracterización, lo referimos al resultado del proceso de producción de un objeto de conocimiento propiamente dicho, siendo este la caracterización de la religión/religiosidad en Wittgenstein; por otra parte, para Weber, el tipo ideal es un principio para la producción del conocimiento de un objeto ya asumido como fenómeno real. Se podría decir que, metodológicamente, utilizamos el "tipo ideal" a la inversa o, como ya se ha mencionado, como algo más afín a la concepción de "constelación". Ahora bien, como también se ha dicho más arriba, mantenemos también el aspecto de la exageración de las características propio de un tipo ideal por su especial utilidad en el presente trabajo. Esto se debe a que la naturaleza particular y única que Wittgenstein tiene de su propia religiosidad personal no permite una clasificación categorial al uso, sino que se tienen que "exagerar" ciertos aspectos para que estos cuadren con una caracterización aprehensible para el aparataje conceptual sociológico del que disponemos.
} 
Ahora bien, como consideración preliminar y antes de empezar con el análisis de fragmentos queremos apuntar que las concepciones religiosas de Wittgenstein van de la mano de uno de sus aportaciones filosóficas más importantes, los juegos de lenguaje y, a su vez, en esta cuestión hay que tener a su vez presente el concepto de "forma de vida". Utilizamos el siguiente fragmento para ilustrar esta relación entre lo religioso, lo filosófico y lo social:

[78] Se dice con frecuencia que la nueva religión decreta que los dioses de la antigua son demonios.

Pero en realidad, estos ya se habían hecho demonios (Aforismos: Cultura y valor, p. 53).

Esta cita respecto al cambio en la consideración sobre figuras divinas y su significado permite poner en relación las consideraciones religiosas con el aspecto propiamente filosófico que las fundamentan, y a su vez el aspecto social implícito. Los juegos de lenguaje responden en su desarrollo a un contexto en el cual se llevan a cabo y, en consecuencia, tanto los términos y expresiones como aquello a lo que refieren son propiamente contingentes de este mismo contexto, que es propiamente práctico y social. La filosofía de Wittgenstein (en este punto], ejercida como una observación de segundo orden, tiene una de sus pretensiones en mostrar [que no explicar] el funcionamiento y desarrollo de los juegos de lenguaje, pero siempre como realidades concretas que se dan siempre como un uso del lenguaje en cuestión; el centro de interés son las prácticas propiamente dichas y los juegos de lenguaje mediante los que se articulan éstas. A su vez, la forma de vida fundamenta el contexto práctico en el que el juego de lenguaje media entre los individuos que de él participan y articula la propia práctica comunicativa necesaria para el contexto en cuestión; es una especie de "concepción del mundo" compartida por todos los individuos que participan de un juego de lenguaje comprendido en ella en un cierto momento y lugar [Investigaciones filosóficas, p. 107).

En este sentido, la cuestión de aquello que podría ser fundamento o causa de un lenguaje queda para Wittgenstein también en el ámbito de la contingencia ${ }^{4}$. Por tanto, los juegos de lenguaje en su contingencia dependen de un contexto social variable, y estos juegos pueden aparecer entre dos personas, dentro de un grupo o pueden ser compartidos por una sociedad entera; a su vez las formas de vida que tienen a la base poseen la misma variabilidad:

La expresión <juego de lenguaje> debe poner de relieve aquí que hablar el lenguaje forma parte de una actividad o de una forma de vida [Investigaciones filosóficas, p. 107).

En consecuencia, respecto al fragmento de los Aforismos, la condición de la emergencia de una nueva religión que permite designar a los viejos dioses como demonios obedece a una condición social contingente en la cual [1] existe la posibilidad práctica de esta emergencia de nuevos sentidos enmarcados en nuevos juegos de lenguaje, pero la observación de segundo orden solo puede ver esta emergencia como resultado ya efectivo, no puede constatar su causa (en términos del propio Wittgenstein, se trata de mostrar los usos, no de explicar los fundamentos de su uso]; y [2] la designación negativa de los antiguos dioses puede guardar relación con una consideración también negativa respecto a la situación social anterior a la nueva religión, de la cual habían surgido los antiguos dioses, y esta consideración negativa queda plasmada en un nuevo juego del lenguaje posibilitado por nuevas prácticas que cambian la situación social y que a su vez suponen el cambio en la consideración de los antiguos dioses. La negatividad hacia éstos ya existía, pero aun no se había podido articular como lenguaje porque la situación practica del contexto no lo permitía, la forma de vida aun no admitía esa consideración; ya eran considerados

$4 \quad$ Apuntar que esta descripción es ya una lectura en cierta manera de carácter sociológico respecto a estas proposiciones encontradas en las Investigaciones filosóficas, pero intentando no desviarse en exceso del posible sentido original. 
como demonios en tanto representación de una situación social [forma de vida] caracterizada como negativa por algunos de los individuos participantes en ella, pero aun no había surgido un juego de lenguaje religioso (posibilitado por un cambio en las prácticas que permite el surgimiento de una nueva religión] que permitiría designarlos como tales.

Por otra parte, también sobre la consideración de Dios:

\begin{abstract}
Una vez dices <Dios ha creado el mundo> \& otra <Este ser humano es - Dios>. Pero no piensas que este ser humano haya creado el mundo, \& sin embargo hay aquí una unidad. Tenemos dos representaciones diferentes de Dios: o tenemos dos representaciones diferentes \& utilizamos para ambas la palabra Dios (Movimientos del pensar, p. 127).
\end{abstract}

Una vez más, aparece la palabra Dios como poseyendo un sentido y significado contingente, dependiente por tanto del juego de lenguaje en que se esté empleando. Ahora bien, el término Dios, en algunos de sus sentidos, sí apela a una cierta esfera que tiene que ver con los fundamentos del modo de vida; en esta acepción, el término Dios sirve como punto nodal de una cierta consideración respecto al mundo y a la vida que a su vez fundamenta la acción de los individuos en el mundo según sea esta consideración. La palabra Dios ligada un cierto tipo de espíritu y usada en ciertos juegos de lenguaje apela a un fundamento ético, en tanto que, como símbolo, refiere a un conjunto prescriptivo de posibilidades prácticas que se supone son aceptadas y seguidas por todos los individuos a los que ese símbolo une como comunidad. Sin embargo, es importante aclarar que no todos los fenómenos religiosos requieren de una figura divina o Dios al que apelar para generar una comunidad de individuos. En este sentido, lo religioso es algo propiamente social y convenido, fruto de un contexto de interacción entre individuos y que tiene a su base unas prácticas que mediante juegos de lenguaje expresan algo que está más allá de las prácticas y el mundo material como tal.

La cuestión de la contingencia y contextualización de los juegos de lenguaje, así como de las palabras en ellos utilizadas aparece también respecto a la Biblia:

Con la Biblia no tengo ante mí nada más que un libro. Pero ¿por qué digo <nada más que un libro>? Tengo un libro ante mí, un documento, que por sí solo no puede tener más valor que otro documento cualquiera [Movimientos del pensar, p. 97].

A lo religioso en general:

En la religión debería suceder que cada grado de religiosidad correspondiera a un tipo de expresión, que no tuviera sentido en un grado inferior. Para quien esté ahora en el grado inferior, es nula y vana esta doctrina que tiene significado en uno superior; sólo puede ser entendida falsamente y además estas palabras no son válidas para este hombre [Aforismos: Cultura y valor, p. 77).

A los milagros:

Si se quieren interpretar los milagros de Cristo, por ejemplo, el milagro de las bodas de Caná [...]. Lo milagroso ha de ser aquello que proporciona contenido \& significado a esa acción. Y con ello no me refiero a lo extraordinario, o a lo que no ha sucedido nunca, sino al espíritu con el que se hace algo así y del que la transformación del agua en vino es sólo un símbolo, un gesto [por así decirlo]. Un gesto que [efectivamente] sólo puede hacer quien es capaz de hacer eso extraordinario. Si ha de decirnos algo, hay que entender el milagro como gesto, como expresión. También podría decir: Sólo es un milagro cuando lo hace alguien que lo hace con un espíritu milagroso. Sin ese espíritu se trata sólo de un hecho extraordinariamente raro. Es como si hubiera de conocer ya a la persona para poder decir que se trata de un milagro. Tengo que entender la totalidad ya con el espíritu correcto para sentir que ahí se produce un milagro. (Movimientos del pensar, p. 60). 
Se aprecia en estas citas que las cuestiones religiosas y su consideración obedecen a una situación social en la que los individuos ya están insertos, la cuales a su vez conllevan un cierto espacio social común y, por tanto, consideran de antemano los motivos religiosos y sus diferentes manifestaciones como algo propiamente religioso por cuanto ellos mismos siempre han participado de la forma de vida de las que emergen y se han impregnado del espíritu del cual estas derivan en su modo de consideración.

Así, las formulaciones religiosas, en este sentido, caen dentro del epígrafe número 7 del Tractatus [p. 71], en tanto que forman parte de aquello de lo que no se puede hablar en un sentido propiamente científico/lógico racional. Ahora bien, que no obedezcan a una racionalidad de carácter científico no significa que sean irracionales, sino que no obedecen a la racionalidad lógico-científica propiamente dicha; en este sentido, Weber estaría de acuerdo en que las cuestiones religiosas obedecen a formas de racionalización y racionalidad propias en tanto que se ejerzan como acción racional [Weber, 1979, p. 328]. No por nada el propio Wittgenstein se desmarcó a lo largo de su vida de algunas de las formulaciones del Tractatus, entre ellas este último epígrafe. Obviamente se puede hablar, y de hecho se habla, por ejemplo, de lo religioso; pero esto posee una lógica y "racionalidad" propias en tanto que juego de lenguaje en función de una forma de vida, unas condiciones socio-prácticas y un espíritu, formando todo esto un contexto [caracterizable sociológicamente] del cual los individuos están participando desde el principio, lo sepan o no. En referencia a esto último:

\begin{abstract}
Es curioso que se diga que Dios ha creado el mundo, \& no: Dios crea, continuamente, el mundo. Pues por qué tiene que ser un prodigio mayor que el mundo haya comenzado a ser, que continúe siendo [...] Y si uno se imagina a Dios como creador, ela conservación del universo no tiene que ser un prodigio tan grande como su creación, - sí, no son ambos lo mismo? ¿Por qué he de postular un único acto de creación \& no un acto permanente de conservación - que comenzó una vez, que tuvo un comienzo temporal o, lo que se reduce a lo mismo, una creación permanente? [Movimientos del pensar, p. 123).
\end{abstract}

En base a este fragmento se puede hacer ejemplificar la cuestión de la convención social implícita en aspectos como el espíritu y la forma de vida y, en consecuencia, la religión como tal y los juegos de lenguaje como modos de expresión. En su caracterización de ciertos aspectos de algunas sociedades "primitivas" [aquello a lo que comúnmente se refiere como "sociedades de cazadores y recolectores"], Thorstein Veblen observa el gran valor social que se le atribuye a la "hazaña" como acto carismático [en sentido weberiano] extraordinario [actos como la victoria en batalla contra otro grupo o el abatir a un animal difícil de cazar], en tanto que las tareas de conservación y reproducción del propio grupo [elaboración de medios de vida en general como pieles o alimentos, cuidado de los asentamientos, etc...] se veían bajo una consideración poco favorable, no prestigiosa, por no decir directamente negativa (Veblen, 1987). Por otra parte, una de las características del carisma en este sentido es su necesidad de renovación, la prueba constante de su posesión [Weber, 1979, pp. 193-194]. Ahora bien, estos actos extraordinarios, con el desarrollo de las agrupaciones sociales, pueden entrar en un proceso de racionalización que lleva a su institucionalización y sus consecuencias derivadas [articulación como doctrina, etc.]. Podemos establecer [al menos en un nivel lógico-teórico a priori] una cierta correspondencia entre [1] la consideración de la hazaña en sentido vebleniano, [2] su institucionalización en el proceso histórico para con un cierto espíritu, y [3] cómo este espíritu, compartido obviamente por un cierto número [indefinido] de individuos, considera más importante en su consideración de Dios la creación del mundo equivalente a la hazaña que su conservación del mundo como tal, que caería del lado de la "burda reproducción". 
Queda así remarcado el carácter social y grupal/comunitario que tienen los elementos religiosos en Wittgenstein; estos tienen que ser convenidos y compartidos por más de un individuo como espíritu común para poder ser expresados mediante juegos de lenguaje. Lo religioso formulado mediante el espíritu, la forma de vida y los juegos de lenguaje tiene su esencia en que debe ser posible categorizarlo como tal por varios individuos, aunque estos mismos individuos no tienen por qué ser conscientes de su participación en el espíritu que así lo caracteriza; el fundamento se encuentra siempre en las posibilidades de las prácticas en que están insertos. Este argumento sobre la participación es contrastable con las propias consideraciones de Wittgenstein respecto a y en los prólogos de sus obras, en los que alude a que solo podrán apreciar y comprender los contenidos de sus libros quien, ya participe del mismo espíritu o pensamiento en que han sido escritos [Tractatus, p. 5 y Aforismos, p. 38].

La observación filosófica de segundo orden que propone Wittgenstein permite mostrar cómo estos aspectos [forma de vida, espíritu, religión, etc.] se articulan en un contexto social de uso práctico del lenguaje como juego.

\section{CARACTERIZACIÓN SOCIOLÓGICA DE LA CONCEPCIÓN RELIGIOSA PERSONAL DEL PROPIO WITTGENSTEIN}

Una vez tratados los aspectos generales de la concepción wittgeinsteniana de lo religioso [al menos en la extensión que nos permiten las exigencias formales de este trabajo, el cual no podemos olvidar que es de carácter académico y evaluativo], pasamos a analizar sociológicamente la religiosidad personal del propio Wittgenstein la cual es, cuanto menos, singular y exclusivamente propia en su modo de plantearla. Sin embargo, al mismo tiempo, consideramos que su concepción personal de la religión es consecuente y coherente con la formulación de su filosofía una vez renuncia a las limitaciones establecidas en el Tractatus.

En la "Conferencia sobre ética", ya de manera explícita y pública, se aprecia un distanciamiento de la propuesta del epígrafe 7 del Tractatus, ya que, aunque los fenómenos de carácter ético caen fuera de la lógica propuesta en el Tractatus se puede observar que, efectivamente, los individuos hablan igualmente sobre estas cuestiones. En este sentido, es posible que este sea uno de los principales puntos del viraje desde una lógica unitaria y fundamental del lenguaje hacia una formulación contextual en base a prácticas articulada mediante juegos. Así, los juegos de lenguaje religiosos se articulan en estos espacios prácticos contextuales que, por definición, tienen que ser compartidos, tal como se ha visto en el desarrollo del apartado anterior. En referencia a lo religioso, Wittgenstein y Weber estarían, una vez más, de acuerdo:

\footnotetext{
Toda acción originada por motivos religiosos o mágicos es [...] una acción racional, por lo menos relativa: si no es necesariamente un actuar según medios y fines, sí, desde luego, conforme a reglas de experiencia. [...] El actuar o el pensar religioso [...] no puede abstraerse, por consiguiente, del círculo de las acciones, con vistas a un fin, de la vida cotidiana... [Economía y sociedad, p. 328).
}

Con esta alusión a "reglas de la experiencia" y su vínculo con la vida cotidiana nos situamos en correspondencia con el espacio weberiano de la ética, en tanto que esta sirve de fundamento que impulsa la acción y puede tener su base en diferentes aspectos. Esta ética encuentra su correspondencia en el esquema de Wittgenstein como el espacio de articulación entre la forma de vida, el espíritu y el lenguaje como juegos. Sería esta la esfera de la práctica religiosa, del hacer en sentido enfático, y su contexto de posibilidades prácticas como fundamento para su articulación lingüística. Esta articulación lingüística mediante un juego resulta en la simbolización 
de un aspecto que une a la comunidad participante de un mismo espíritu, como se ha visto más arriba, por ejemplo, respecto a los milagros.

Este viraje de Wittgenstein hacia una filosofía dependiente de los contextos donde se aplica y, por tanto, contingente en sus contenidos y formas, permite la articulación de lo religioso como espacios con una racionalidad y lógica propias la cual solo pueden entender los mismos participantes, que se asume que poseen el espíritu adecuado para participar en la religiosidad de la comunidad a la que pertenecen. Sin embargo, la religiosidad del propio Wittgenstein se desmarca de esta propuesta comunitaria de los juegos de una manera muy peculiar. Partimos de Durkheim para realizar esta caracterización:

\begin{abstract}
Una religión es un sistema solidario de creencias y prácticas relativos a cosas sagradas, es decir, separadas, prohibidas, creencias y prácticas que unen en una misma comunidad moral, llamada Iglesia, a todo los que se adhieren a ella. [...] ... la idea de religión es inseparable de la idea de lglesia, hace presentir que la religión debe ser algo esencialmente colectivo. (Las formas elementales de la vida religiosa, p. 98].
\end{abstract}

A modo de aclaraciones, [1] cuando Durkheim alude a la moral se refiere a relaciones sociales en sentido estricto, que aquí caracteriza como las habidas en una comunidad religiosa, y [2] el término Iglesia refiere estrictamente a un modo de relación social que se corresponde con la comunidad religiosa como institución social ${ }^{5}$. Una vez dicho esto, Wittgenstein podría estar de acuerdo con el carácter colectivo de lo religioso, sea cual fuera su formación y sus características, las cuales aquí Durkheim si entra a describir brevemente. En cierta manera las diferentes formas de la Iglesia a la que alude Durkheim podría tener su correspondencia con distintas formas de espíritu en base a formas de vida y condiciones prácticas que podrían aparecer en Wittgenstein. Por otra parte, para Durkheim un individuo es un ser doble: tiene [1] un ser individual y [2] un ser social [Durkheim, 1967], y en tanto que ser social participaría de la actividad colectiva de la religión. Sin embargo, siguiendo esta división durkheimiana, aparece aquí la ruptura de la religiosidad de Wittgenstein con una caracterización sociológica de este tipo; y es que la religiosidad de Wittgenstein, la suya propia, tal como él mismo la caracteriza, no tiene una forma comunitaria, sino que es exclusivamente suya.

En este punto aparece también una de sus principales divergencias con Tolstoi: en tanto que en este autor se mantiene la forma comunitaria como el punto de salvación del individuo, Wittgenstein, en tanto que admitiendo esto para el resto de individuos y sus juegos del lenguaje, parece que se niega a sí mismo esta posibilidad. Parece que el único juego de lenguaje propiamente privado que "admite" como existente [aunque parece que nunca lo caracteriza explícitamente como tal] es el de su propia religiosidad y su relación con Dios. En tanto que en Tolstoi se da una entrega a la comunidad y por tanto se admite el actuar en un cierto sentido político, Wittgenstein considera más importante que el espacio del actuar sea el del hacerse a sí mismo, el darse de sí. Esto puede apreciarse, entre otras cosas, en la cuestión del carácter de los prólogos que se ha apuntado más arriba, por cuanto Wittgenstein se sitúa a sí mismo en una esfera espiritual que parece estar solo, al menos tal y como lo formula en estos pasajes. Por otra parte, es posible que ésta cuestión del "individualismo religioso", por darle un nombre, esté atravesada por los sentimientos de vanidad y superioridad que Wittgenstein expresa sentir a menudo y que lo situarían en un espacio personal separada de otros individuos:

Debe desmontarse el edificio de tu orgullo. Y es una enorme tarea. (Aforismos: Cultura y valor, p. 67).

$5 \quad$ En sentido específicamente durkheimiano como aquellos hechos sociales que produce moral, relaciones sociales solidarias propiamente dichas. 
Todo o casi todo lo que hago [...] están teñidas de vanidad \& lo mejor que puedo hacer es, por así decirlo, separar la vanidad, aislarla \& a pesar de ella hacer lo correcto, aunque siempre asome. Ahuyentarla no puedo. Sólo a veces no está presente [Movimientos del pensar, p. 29].

Ensucio todo con mi vanidad [Movimientos del pensar, p. 61).

A la conciencia cargada de culpa le sería fácil confesar; la persona vanidosa no puede confesarse [Movimientos del pensar, p. 75].

Cuando digo que quiero deshacerme de la vanidad es cuestionable si no lo quiero solo por vanidad también. Soy vanidoso \& en tanto que soy vanidoso mis deseos de mejora son vanidosos también... [Movimientos del pensar, p. 81].

En relación a esto, también parece mostrar una tendencia a escindirse respecto al resto de individuos y situarse en una esfera propia [quizá superior] en lo intelectual y lo personal:

Creo que mi aparato mental está construido con extraordinaria complicación \& finura\& por eso con una sensibilidad más que normal. Hay muchas cosas que le perturban, le pone fuera de servicio lo que no perturbaría a un mecanismo más tosco... [Movimientos del pensar, p. 43].

Nada me resulta más difícil que sentirme inferior... (Movimientos del pensar, p. 110).

No podemos afirmar fehacientemente una relación de causalidad entre los sentimientos de vanidad y superioridad de una parte y el aislamiento religioso de otra, pero a efectos argumentativos es posible que exista una correspondencia, o al menos podemos afirmar su coherencia dentro del esquema sociológico que se está intentando articular en este trabajo. Este argumento se puede reforzar con la cita siguiente:

Casi podría considerarme como un núcleo amoral al que fácilmente se le adhieren los conceptos morales de otras personas [Movimientos del pensar, p. 72].

Aquí se expresa una vez más el carácter individual y aislado de la concepción religiosa de Wittgenstein. Se supone, siguiendo a Durkheim, que los individuos participan de las formas morales en tanto que encarnaciones colectivas de relaciones sociales compartidas, propiamente solidarias y comunitarias, pero Wittgenstein se sitúa fuera de este espacio social en cuanto a los conceptos morales como normativos ${ }^{6}$, y por tanto en un plano religioso propio y singular. En este sentido, Wittgenstein habría llegado a una concepción religiosa interior que Durkheim apunta como aspiración y tendencia en su época, pero que deja fuera de su concepción propiamente sociológica de la religión:

\begin{abstract}
Quedan aún las aspiraciones contemporáneas hacia una religión que consistiera enteramente en estados interiores subjetivos, y que fuera construida libremente por cada uno de nosotros. Pero por reales que fueran no podrían afectar a nuestra definición; [...] se puede definir las religiones tal como son y tal como han sido, no tal como, más o menos vagamente, tienden a ser (Durkheim, 1993, pp. 97-98].
\end{abstract}

Parece pues que Wittgenstein como hombre religioso forma parte de esta tendencia que describe Durkhiem, siendo una realización de la misma. A su vez, y desde una posición weberiana, se podría caracterizar a Wittgenstein, en tanto que poseedor de una religiosidad interior subjetiva y propia, como una especie de profeta en tanto que portador carismático de un tipo especial de religiosidad:

Con el nombre de "profeta" queremos comprender aquí un puro portador personal de carisma, cuya misión anuncia una doctrina religiosa o un mandato divino. En esto no queremos hacer ninguna

$6 \quad$ La normatividad de la moral durkheimiana está implícita en las mismas relaciones en tanto que son éstas son las que son y no otras, así como que cumplen una función en el tipo social en que existen. 
distinción fundamental en cuanto a que [...] aparezca como "renovador" o "fundador" de religión" [Weber, 1979, p. 356].

Ahora bien, esta caracterización como profeta es solamente formal como descripción de la figura carismática que puede poseer Wittgenstein (por ejemplo, de nuevo, en su redacción de prólogos y sus logros en el campo intelectual], ya que éste, por su parte, no pretende conformar una comunidad. Parece que no considera que su espíritu propio y personal pueda comulgar con otras formas espirituales comunitarias a las que se adhieren otros individuos. Esto es a la vez coherente con su concepción de lo religioso en general, el espíritu y los juegos de lenguaje, por cuanto solo se participa de ellos en tanto que ya se está inserto en la posibilidad de ejercer esta misma participación que siempre se ha compartido; pero en este sentido, el espíritu del propio Wittgenstein es "único", solo suyo y no asimilable a otros modos de espiritualidad. También es posible que este carisma que Wittgenstein efectivamente posee y manifiesta sobretodo en el plano intelectual sirva como afirmación de la sensación de superioridad que expresa, resultando en una retroalimentación con el sentimiento de vanidad y el aislamiento religioso y personal resultante.

En este sentido, la religiosidad de Wittgenstein también se desmarca de la reflexión de Bourdieu, el cual añade a los intentos competitivos por establecer concepciones religiosas dominantes el elemento de aquellos individuos a los que se apela e intenta convencer para conformar la comunidad simbólica [Bourdieu, 1971] estando este elemento de convicción congregacional ausente en la concepción wittgeinsteniana de su religiosidad. Caracterizamos así la religiosidad de Wittgenstein como subjetiva y propia, únicamente suya y solo comprendida por su propio espíritu, el cual, por razones que aquí no podemos entrar a tratar, no es capaz de entrar en una relación religiosa significativa con otras formas espirituales que sí son compartidas por otros grupos de individuos en comunión.

En cuanto a lo específico de la "doctrina" religiosa personal de Wittgenstein, esto es caracterizable en diferentes aspectos. Sobre su relación con Dios:

\begin{abstract}
¡Dios, permíteme llegar a una relación contigo en la que pueda estar satisfecho con mi trabajo! ¡Cree que Dios puede exigir todo de tí en cualquier momento! ¡Sé consciente realmente de eso! ¡Pide después que te conceda el regalo de la vida! ¡Puesto que en cualquier momento puedes caer en la locura o volverte completamente infeliz si no haces algo que se te pide! [...] ¡Conserva mi entendimiento puro y sin mancha! [Movimientos del pensar, p. 109).
\end{abstract}

Hoy me fue mejor en el trabajo; gracias a Dios. Me pareció que volvía a haber algún sentido en el trabajo. (Movimientos del pensar, p. 125).

Quiera Dios dirigir mi vida de modo que se vuelva de otro modo (Movimientos del pensar, p. 128).

Que quieras discutir con Dios significa que tienes un falso concepto de Dios, que estás en una superstición. Tienes un concepto incorrecto cuando te enfadas con el destino. Debes reorganizar tus conceptos. Satisfacción con tu destino tendría que ser el primer mandamiento de la sabiduría [Movimientos del pensar, p. 128].

En este caso, Dios aparece como un centro ético fundamental para Wittgenstein en tanto que en base a su relación con él siente el impulso práctico para la acción y la vida en general, y a la vez esta relación bien llevada supone un alivio psicológico para el estado espiritual. Esta cuestión del alivio al seguir una buena ética es contravenida por el pecado ético, en el cual Wittgenstein parece incurrir por momentos cuando afirma sentirse miserable y apartado de Dios:

La contravención de la voluntad del dios es ahora un "pecado" ético, que pesa sobre la "conciencia", independientemente de las consecuencias inmediatas. Los males que caen sobre el individuo son 
calamidades queridas por el dios y consecuencia del pecado; y el individuo trata de librarse, de "salvarse", mediante una conducta "piadosa" agradable a la divinidad [Durkheim, 1993, p. 354].

A su vez y en relación a los fragmentos anteriores, parece que la ética de Wittgenstein, en este sentido práctico, cobra forma a través del ejercicio competente en su trabajo, en su labor productiva y desempeño intelectual o, en otras palabras, en su hacer en el mundo, siendo esto aquello que lo puede reconciliar con Dios. En referencia a esto, Weber afirma que, en ciertas concepciones protestantes, el desempeño competente en el oficio o trabajo es lo que le confirma al individuo la posesión de la gracia divina, la cual sirve al alivio psicológico ya mencionado frente a la miseria del espíritu:

\begin{abstract}
La palabra bíblica, tan acentuada también por Lutero: "permanece en tu oficio" es aquí elevada a una obligación religiosa cardinal y sancionada por consecuencias religiosas graves. [Weber, 1979, p. 354). ${ }^{7}$

... el asceta contrasta su estado de gracia mediante su actuar. [...] Cuando el asceta obra en unidad consigo mismo está seguro de ser un instrumento de Dios. Su obligada humildad de criatura es, por lo mismo, de dudosa autenticidad. El éxito de su acción es ya un éxito del mismo Dios, al que ha colaborado, o por lo menos una señal de su bendición especial para él y para su obra. (...) Para el asceta se prueba la certidumbre de la salvación en la acción racional, unívoca según sentido, medios y fines, según principios y reglas (Weber, 1979, pp. 432-433).
\end{abstract}

Ahora bien, aunque el fundamento ético de Wittgenstein [que tiene que ver con su espíritu y forma de vida] puede corresponderse con el impulso ético a la acción de estos tipos de protestantismo [especialmente los de origen protestante], hay una divergencia fundamental por cuanto el Dios de Wittgenstein no se encuentra en una esfera insondable, sino que Wittgenstein admite, como hemos visto en los extractos, un cierto tipo de comunicación o interacción con él. Esta forma insondable de Dios en el protestantismo calvinista recurre a una idea de predestinación que no parece ser realmente importante para la concepción religiosa de Wittgenstein, situándose él en un grado de religiosidad distinto al requerido para aceptar algo así:

Por ejemplo, la doctrina de la predestinación en Pablo es, en mi grado, irreligiosidad, un horrible absurdo. Por ello, no me pertenece, pues sólo puedo usar erróneamente la imagen que me ofrece. Es una imagen piadosa y buena, pero para un grado muy distinto, en el que uno debe guiarse en la vida de modo totalmente distinto a como yo podría hacerlo. [Aforismos: Cultura y valor, p. 77].

Al desmarcar su concepción religiosa y ética de la predestinación, se da un desplazamiento que pone el núcleo del impulso ético (y por tanto práctico) propio de Wittgenstein en la fe, la cual es caracterizada de la siguiente manera:

Me parece que una fe religiosa podría ser algo así como el apasionado decidirse por un sistema de referencias. Como si además de ser fe, fuera una forma de vida o una forma de juzgar la vida. Una aprehensión apasionada de esta concepción. Y la instrucción en una fe religiosa debería ser, pues, la exposición, la descripción de ese sistema de referencias y a la vez un hablar-a-la-conciencia. $Y$ al final ambos deberían tener el efecto de que el instruido mismo, por sí, apresara apasionadamente ese sistema de referencias. Es como si, por una parte, alguien me dejara ver mi situación desesperada y, por otra, pusiera ante mí el instrumento de salvación, hasta que yo, por mí mismo, o en todo caso no llevado de la mano por el instructor, me lanzara sobre ello y lo apresara. [Aforismos: Cultura y valor, p. 122].

No la biblia, solo la conciencia puede ordenarme... [...] Creer no como se cree en algo probable, sino en otro sentido. Y sólo puede reprochárseme mi falta de fe en tanto en cuanto mi conciencia me ordena

$7 \quad$ Para un estudio en profundidad de esta cuestión del protestantismo y sus ramificaciones éticas y morales en referencia al trabajo, ver Weber, M. [2011]. La ética protestante y el espíritu del capitalismo. México: Fondo de Cultura Económica. 
creer - si es que algo así es posible - o me reprocha bajezas que de un modo que ignoro no me dejan llegar a la fe. [...] Ahora no puedes saber absolutamente nada de una fe así, tiene que ser un estado de espíritu del que no sabes absolutamente nada y que no te importa nada mientras tu conciencia no te lo revele; [...] Para ti no puede haber disputas sobre la fe ya que no sabes [no conoces] de qué se disputa. [...] La fe comienza con la fe. Hay que comenzar con la fe; de las palabras no se sigue fe alguna. Basta. [Movimientos del pensar, p. 98].

Esta concepción de fe es lo que vehicula la concepción de la religiosidad de Wittgenstein y, como conciencia del mundo y lo real, está en un vínculo directo con la forma de vida que a su vez produce el espíritu de Wittgenstein como sujeto. Alrededor de esta noción gravita también la concepción de Dios, en tanto que en Wittgenstein parece actuar como el centro del sistema de referencias junto con su relación con el trabajo como modo de llegar a Dios y recibir así alivio psicológico o, en terminología de Wittgenstein, sentir felicidad y no miseria. A su vez, los aspectos propiamente morales y normativos pertenecientes a la esfera de la creencia quedan en un segundo plano. El fundamento de la religiosidad es la ética, el impulso práctico, y a la base de esta se encuentra la fe como sistema de referencias; esta apela de manera directa a la conciencia del mundo, y por tanto a la forma de vida como contexto en el que son posibles unas prácticas y no otras. Por otra parte, esto es vinculable con la caracterización weberiana de ciertos tipos de fideísmo:

\footnotetext{
... salvación en la fe. En tanto como este concepto no se identifica con el sometimiento a normas prácticas, supone siempre el tener por verdaderos supuestos hechos metafísicos; por consiguiente, un cierto desarrollo de "dogmas" cuya aceptación vale como como señal esencial de pertenencia [Weber, 1979, p. 443].

\begin{abstract}
... la religiosidad fideísta supone siempre un dios personal, [...] en cuyo favor habrá que renunciar en algún punto al propio tener razón (Weber, 1979, p. 447).

Por lo regular la religiosidad fideísta actúa de un modo completamente antirracional sobre el modo de llevar la vida cuando la relación con Dios o con el Salvador muestra el carácter de devoción apasionada y la fe un ingrediente erótico latente y, con frecuencia, manifiesto [Weber, 1979, p. 450).
\end{abstract}

Parece así que la religiosidad de Wittgenstein tiene un elemento fideísta bastante significativo, al menos desde esta caracterización weberiana. Este argumento se puede reforzar siguiendo la relación entre fe y pasión, y esto en contraposición al saber:

La sabiduría es algo frío y, en esta medida, tonto. [La fe, por el contrario, una pasión]. También podría decirse: la sabiduría sólo te encubre la vida [Aforismos: Cultura y valor, p. 111].

Recordamos aquí también la cita anterior en la que se refiere a la fe como "el apasionado decidirse por un sistema de referencias".

Este papel de la pasión en contraposición a la creencia que ya incluye un sistema de valores y, por tanto, juicios, pone en claro que, al menos en lo religioso, Wittgenstein reniega de las formas doctrinarias que ejercen un sometimiento en base a elementos abstraídos del contexto real práctico. En otras palabras, lo moral puede ser un efecto de un espacio ético de acción, pero si, weberianamente, se produce un proceso de racionalización sobre la ética y la convierte en un sistema racionalizado de creencias que posee su propia lógica separada del fundamento ético, cae en un modo de religiosidad que para Wittgenstein no es fundamental, ni mucho menos nuclear de la experiencia religiosa; es un efecto y no un fundamento. Recordemos aquí, por ejemplo, las citas anteriores sobre que la Biblia como conjunto de creencias y dogmas no dice nada, sino que depende de la fe que estas creencias se adopten como propias. Esta cuestión, una vez más, encuentra una correspondencia en la caracterización weberiana del fideísmo, que a su vez permite profundizar en la posición de Wittgenstein: 
Si no se saca la consecuencia de una aristocracia de intelectuales, entonces la fe tendrá que ser algo distinto que el comprender y tener por verdad un sistema teológico de dogmas. [...] ... la fe religiosa pierde su carácter intelectualista. Tan pronto como la religiosidad se convierte predominantemente en ético-racional, lo posee solo en grado secundario. Pues el mero "tener por verdaderos" los conocimientos le bastará a una "ética de la convicción" a lo sumo como el grado más bajo de fe... [...] También la fe debe convertirse en cosa del sentir. La dependencia personal de un dios particular es algo más que "saber", y por eso se la designa como "fe". [...] La "fe" que a Abraham "le fue atribuida a justicia”, no es ningún "tener por verdad" intelectual de dogmas, sino confianza en las promesas de Dios. Lo mismo exactamente significa la fe, según su sentido centra, en Jesús y en Pablo. El saber y el conocimiento de los dogmas retroceden mucho (Weber, 1979, p. 445].

Esta caracterización de Weber parece ser afín a la concepción potencialmente fideísta de Wittgenstein, en tanto que su concepción religiosa rechaza la dimensión del conocimiento sobre lo religioso, aquella dimensión que es propiamente moral [valorativa] y doctrinaria como sistematización de un sistema de valores que se sitúan por encima de las condiciones prácticas de la ética y ejercen un juicio sobre ellas. Para Wittgenstein, su religiosidad tiene su fundamento en la fe como elección apasionada del sistema de referencias frente al mundo, frente a la dimensión ética propiamente práctica y en base a esta misma. Una vez más, esto es coherente con el planteamiento filosófico de los juegos de lenguaje, en tanto que para participar de estos se tiene que compartir, ya desde el principio, el contexto práctico y la forma de vida, y en el caso de lo religioso, lo espiritual, que posibilita los propios juegos de lenguaje como expresión de las relaciones entre estos aspectos.

Teniendo en cuenta la gran cantidad de reflexiones que Wittgenstein dedica a Jesús como figura religiosa, es posible que el fideísmo separado de la intelectualidad religiosa venga motivado por ciertos aspectos de la doctrina contraria a lo intelectual de la creencia en Jesús que Weber expresa de la siguiente manera:

Jesús conoce dos absolutos "pecados mortales": uno es el "pecado contra el espíritu", que comete el escriba al despreciar el carisma y sus portadores; el otro es decir al hermano "tú, tonto", la soberbia nada fraternal del intelectual contra el pobre de espíritu. Este rasgo antiintelectualista, la condenación tanto de la sabiduría helénica como de la rabínica, es el único elemento "estamental" y muy específico de su nueva [Weber, 1979, p. 490].

Esto se corresponde con la posición crítica de Wittgesntein frente a ciertas ramas del cristianismo en tanto que apelan a formas doctrinarias dogmáticas del conocimiento de las escrituras y los hechos religiosos articuladas por castas sacerdotales y generan formas jerárquicas que separan a los individuos en las posibilidades de la dimensión práctica; los pone en espacios de posibilidades de expresión lingüística diferentes en lugar de unirlos en base a sus posibilidades prácticas. Para Wittgenstein, esta intelectualidad de la creencia no es un aspecto propiamente religioso, sino que obedecen a otras lógicas y condiciones de posibilidad. Como veíamos en una cita anterior, no se puede saber nada sobre una fe así y no se puede disputar sobre ella porque no se sabe ni conoce qué se disputa. En este aspecto, solo el propio Wittgenstein puede sentir su relación con Dios en base a su fe seguida de manera apasionada, y en esta relación encuentra un sentido para su vida en tanto que se realiza religiosamente a través del trabajo. No es posible articular su religiosidad como relación teórica, sino solo como práctica ética, como conciencia frente al mundo que es consecuente con las referencias elegidas apasionadamente con la fe, frente a éste.

A modo de resumen y clausura de este apartado sobre la cuestión de la fe y la consideración que Wittgentein tiene de esta: 


\begin{abstract}
Déjame aferrarme a que no quiero engañarme a mí mismo. Es decir, en mí mismo sólo quiero reconocer siempre como exigencia una exigencia que yo considere como tal. Esto se aviene perfectamente con mi fe. Con mi fe tal como es. De ello se sigue que, o bien cumpliré la exigencia o bien sufriré por no cumplirla, puesto que ni me la puedo reprochar ni puedo sufrir por no estar a la altura [Movimientos del pensar, p. 106].

Creo entender que el estado de espíritu que produce la fe puede hacer bienaventurado al ser humano. Pues cuando el ser humano cree, cree de todo corazón que el perfecto se ha entregado, ha sacrificado su vida por él, que con ello - desde el principio - le ha reconciliado con Dios, de modo que tú ahora no tienes más que seguir viviendo siendo digno de ese sacrificio, - entonces eso tiene que ennoblecerlo, que elevarlo, por decirlo así, a la nobleza. Entiendo - diría - que es un movimiento del alma hacia la bienaventuranza [Movimientos del pensar, p. 129].
\end{abstract}

Así, la fe como pasión que reconcilia con Dios es aquello que permite una vida tranquila y feliz. En el caso de Wittgenstein, esta reconciliación es puramente personal y se basa en una concepción propia y no compartida que parece tener uno de sus fundamentos en el trabajo, en su hacer en el mundo en sentido más o menos "productivo". Parece que Wittgenstein se considera a sí mismo la única excepción existente al carácter colectivo y convenido de los juegos de lenguaje así como de la forma de vida y lo espiritual, por cuanto su concepción personal de lo religioso es propia y no compartida con nadie; es un espíritu singular que no puede relacionarse significativamente [al menos en sentido religioso] con otros espíritus que sí son formas colectivas. Tiene una concepción singular de su propia religiosidad.

Acabamos aquí la sección dedicada a la concepción religiosa personal de Wittgenstein. Somos conscientes de que hemos dejado varios aspectos a tratar tanto en este apartado como en el anterior dedicado a la concepción general, y que la mayoría de los puntos abordados no se han tratado con la profundidad que nos hubiese gustado, pero siendo esto un primer esbozo de un trabajo a ampliar, estas cuestiones pueden ser retomadas en futuros trabajos. los requerimientos formales de extensión no nos permiten tratar más temas ni profundizar más en los abordados aquí. Damos paso así a unas breves conclusiones que intentan devolver lo tratado hasta el momento a su mismo inicio, la concepción filosófica, pero ahora atravesada por todos estos elementos y contenidos.

\title{
4.CONCLUSIONES
}

Volvemos sobre algunas reflexiones de Wittgenstein sobre la filosofía, pero ahora vistas a través de los aspectos tratados en los puntos anteriores:

\footnotetext{
La tarea de la filosofía es tranquilizar el espíritu con respecto a preguntas carentes de significado. Quien no es propenso a tales preguntas no necesita la filosofía [Movimientos del pensar, p. 52].

El movimiento del pensamiento en mi filosofar tendría que reencontrarse en la historia de mi espíritu, de sus conceptos morales \& en la comprensión de mi estado [Movimientos del pensar, p. 79].

El trabajo filosófico - como en muchos aspectos sucede en la arquitectura - consiste, fundamentalmente, en trabajar sobre uno mismo. En la propia comprensión. En la manera de ver las cosas. [Y en lo que uno exige de ellas.] [Aforismos: Cultura y valor, p. 54).
}

$8 \quad$ Algunos de los aspectos a ampliar podrían ser la relación y diferencias con Tolstoi, la cuestión de la salvación, las posibilidades de la vida y su cambio en base a elecciones que cambian el modo de ver las cosas y con ello el lenguaje que describe el mundo y la relación de esto con Dios y la fe, una mayor profundización en la separación entre creencia y fe, la confesión o los milagros; todas estas entre muchas otras cuestiones importantes las cuales no vamos a aludir aquí. 
En este posicionamiento de la filosofía frente a los problemas que le son propios parece que, una vez más, Wittgenstein se sitúa en un espacio individual y personal, separado de otros individuos, para su ejercicio intelectual (recordemos aquí la cita sobre el aparato mental aparecida más arriba]. Si relacionamos esto con su concepción de Dios como aspecto nuclear de su fe, aquello que lo impulsa a la acción y da sentido a su vida y con lo que se relaciona mediante el trabajo, su tarea productiva filosófica, personal e individual, y que a la vez esta tarea alivia su espíritu, se encuentra una correspondencia directa con su propia religiosidad la cual no comparte con otro[s] espíritu[s], y que a la vez, es coherente con los postulados de su filosofía en su mismo ejercicio, en tanto que los juegos de lenguaje permiten articular todas estas dimensiones y aspectos de esta manera, añadiendo la singularidad de que el único juego de lenguaje privado que parece existir para Wittgenstein es el de su propia religiosidad.

La concepción dialéctica de este trabajo hace especialmente dificultosa una exposición sumaria que resuma los contenidos del mismo. Por esto, nos arrogamos a la benevolencia del lector en su consideración comprensiva del desarrollo dialéctico de los elementos en su conjunto y su solapamiento por el ejercicio socioanalítico. Aun así, en esta sección se ha intentado recoger de manera breve y concisa la "totalidad determinada" que este trabajo pretendía construir, el complejo de relaciones que comprende las dimensiones personal, social, filosófica y religiosa general y personal de Wittgenstein como mutuamente necesarias y solidarias las unas con las otras; pero para que esto tenga todo el peso e importancia que le corresponde, remarcamos la importancia de considerar este trabajo en su conjunto como proceso de desarrollo dialéctico.

Somos perfectamente conscientes de que aquí no han sido tratados una gran cantidad de temas importantes para la cuestión que nos ocupa o, en su defecto, no han sido tratados con la profundidad y exhaustividad que merecen y les corresponde. Por nuestra parte remitimos una vez más al carácter provisional y exploratorio de este trabajo y remarcamos que queda pendiente una ampliación considerable de los contenidos expuestos hasta el momento, así como situar los resultados aquí obtenidos en el marco de una investigación mayor como es la caracterización sociológica en general de Wittgernstein. En cuanto al carácter esencialmente limitado, limitador y fragmentario de este ensayo le cedemos la última palabra al propio Wittgenstein, palabra a la cual nosotros nos arrogamos y expresamos como un sentimiento propio y, aunque quizá Wittgenstein no estaría del todo de acuerdo con ello, también como un sentimiento que, en este caso, compartimos con él:

Expreso lo que quiero expresar siempre sólo <a medias>. Y quizá ni siquiera eso, tal vez sólo en una décima parte. Esto significa algo. Mis escritos son con frecuencia sólo un <balbuceo> [Aforismos: Cultura y valor, p. 57).

\section{REFERENCIAS}

Bourdieu, P. [1971]. Una interpretación de la teoría de la religión según Max Weber. Archives Européennes de Sociologie, XII, 1.

Durkheim, E. [1967]. De la división del trabajo social. Buenos aires: Schapire.

Durkheim, E. [1993]. Las formas elementales de la vida religiosa. Madrid: Alianza.

Marx, K. [2010]. Contribución a la crítica de la economía política. Madrid. Biblioteca nueva. [1aㅡ ed., 1857]. 
Veblen, T. [1987]. Teoría de la clase ociosa. Barcelona: Orbis.

Weber, M. [1979]. Economía y sociedad: Esbozo de sociología comprensiva. México: Fondo de Cultura Económica.

Weber, M. [2011]. La ética protestante y el espiritu del capitalismo. México: Fondo de Cultura Económica.

Wittgenstein, L. [1995]. Aforismos: Cultura y valor. Madrid: Espasa Calpe.

Wittgenstein, L. [2000). Movimientos del pensar: Diarios 1930-1932 / 1937-1937. Valencia: Pretextos.

Wittgenstein, L. [2017a]. Investigaciones filosóficas. Marid: Gredos. [1 a ed. alemán, 1953].

Wittgenstein, L. [2017b]. Tractatus logico-philosophicus. Madrid: Gredos. [1 a ed. alemán, 1921]. 